\title{
Inoculation of Mother's Own Milk Could Personalize Microbiological, Metataxonomic and Peptidomic Profile of Pasteurized Donor Human Milk Used for Feeding Preterm Infants
}

Domenica Mallardi ( $\square$ domenica.mallardi@mangiagalli.it)

Fondazione IRCCS Ca' Granda Ospedale Maggiore Policlinico

Chiara Tabasso

Fondazione IRCCS Ca' Granda Ospedale Maggiore Policlinico

\section{Pasqua Piemontese}

Fondazione IRCCS Ca' Granda Ospedale Maggiore Policlinico

\section{Stefano Morandi}

National Research Council: Consiglio Nazionale delle Ricerche

Tiziana Silvetti

National Research Council: Consiglio Nazionale delle Ricerche

Filippo Biscarini

National Research Council: Consiglio Nazionale delle Ricerche

\section{Paola Cremonesi}

National Research Council: Consiglio Nazionale delle Ricerche

\section{Bianca Castiglioni}

National Research Council: Consiglio Nazionale delle Ricerche

Valentina Pica

University of Milan: Universita degli Studi di Milano

\section{Milda Stuknyte}

University of Milan: Universita degli Studi di Milano

Ivano De Noni

University of Milan: Universita degli Studi di Milano

\section{Orsola Amato}

Fondazione IRCCS Ca' Granda Ospedale Maggiore Policlinico

Nadia Liotto

Fondazione IRCCS Ca' Granda Ospedale Maggiore Policlinico

\section{Fabio Mosca}

Fondazione IRCCS Ca' Granda Ospedale Maggiore Policlinico

\section{Paola Roggero}

Fondazione IRCCS Ca' Granda Ospedale Maggiore Policlinico 


\section{Research Article}

Keywords: donor human milk, mother's own milk, preterm infants, bacterial growth, human milk microbiome, peptidomic profile

Posted Date: April 23rd, 2021

DOl: https://doi.org/10.21203/rs.3.rs-439999/v1

License: () (i) This work is licensed under a Creative Commons Attribution 4.0 International License.

Read Full License 


\section{Abstract \\ Background}

Human milk is a vehicle of bioactive compounds and beneficial bacteria which promote the establishment of a healthy gut microbiome of newborns, especially of preterm infants. Pasteurized donor human milk (PDHM) is the second-best option when preterm mother's own milk is unavailable. Since pasteurization affect the quality of donor milk, the effect on bacterial growth, human milk microbiota diversity and proteolytic phenomena in PDHM inoculated with different preterm milk samples, was evaluated.

\section{Methods}

Ten preterm milk samples was used to perform inoculation of PDHM at $10 \% \mathrm{v} / \mathrm{v}$. Microbiological, metataxonomic and peptidomic analysis, on preterm milk samples at the baseline (T0) and PDHM and inoculated milk (IM) samples at T0, after $2 \mathrm{~h}(\mathrm{~T} 1)$ and $4 \mathrm{~h}(\mathrm{~T} 2)$ of incubation at $37^{\circ} \mathrm{C}$, were conducted.

\section{Results}

IM samples at T2 showed a Total Bacterial Count not significantly different $(p>0.01)$ compared to preterm milk samples. Lactic acid bacteria (LAB) level was restored in all IM at T2. After inoculation, metataxonomic analysis showed that Proteobacteria remained the predominant phylum while Firmicutes moved from $3 \%$ at T1 to $9.4 \%$ at T2 in IM samples. Peptidomic profile of IM resembled that of PDHM incubated for the same time in terms of number and type of peptides.

\section{Conclusion}

The study demonstrated that inoculation with fresh mother's own milk could restore bacterial growth and personalize human milk microbiome in PDHM. This effect could be beneficial thanks to the presence of maternal probiotic bacteria which make PDHM more similar to mother's own milk.

\section{Background}

Human milk (HM) represents the optimal feeding for infants, not only for its nutritional quality, but also for being a rich source of several bioactive compounds and specific peptides, essential for the development of the newborn's immature immune and digestive systems (1). HM hosts a complex community of bacteria, the HM microbiome, which comprises many viable commensals, mutualistic or potentially probiotic bacteria. Lots of these bacteria are indigenous, supported by the entero-mammary translocation, but maternal and environmental factors can contribute to shape HM microbiome composition, leading to a high inter-individual variability of microbial species in $\mathrm{HM}(2 ; 3)$. HM 
microbiome plays a beneficial role for the breastfed infants. The constant intake, during lactation, of beneficial bacteria present in the HM promotes the establishment of a healthy gut microbiome of newborns, which limits the growth of potential pathogens, by exerting a protective and nutritive role, especially for preterm infants $(4 ; 5)$.

Mothers who delivered prematurely often experience significant difficulties in breastfeeding their infants. For this reason, the majority of mothers of very preterm infants are able to express small volumes of their own milk (6) and, when mother's own milk is not available or insufficient, donor HM is the second-best option (7).

As recommended by current international guidelines $(8 ; 9)$, donor HM must be pasteurized, using the Holder method, to destroy potential pathogenic microorganisms and retain the ability to inhibit bacterial growth. Although it is important to guarantee microbiological safety, Holder pasteurization leads to a total or partial decrease in the biological quality and effectiveness of donor $\mathrm{HM}$, inactivating most of the valuable HM microbiota species (10). Indeed, the probiotic effect of pasteurized donor HM (PDHM) is not comparable with the probiotic effect of mother's own milk (11). Moreover, HM microbial species hydrolyze milk proteins, due to the potential action of bacterial proteases/peptidases. Other proteolytic phenomena can occur upon the action of the endogenous proteases, some of these originating within the mammary gland and acting during the whole lactation period. Therefore, both HM endogenous enzymes and microbiome can release peptides or degrade specific individual milk proteins with several functional properties (12).

Recently, it has been reported that incubating donor HM with preterm mother's own milk (preterm milk, PM) may be effective in improving the biological quality of donor HM by restoring the original milk microbiome (4). On these bases, an in vitro study was conducted to evaluate the effect on bacterial growth, HM microbiota diversity and proteolytic phenomena in PDHM inoculated with different PM samples.

\section{Methods}

\section{Experimental design}

Ten samples of inoculated PDHM (hereafter named as IM1 to IM10) were obtained by adding ten different fresh PM samples (hereafter named as PM1 to PM10) at $10 \%(\mathrm{v} / \mathrm{v})$. Then, the IM samples were incubated at $37^{\circ} \mathrm{C}$ for $4 \mathrm{~h}$. The PDHM and IM samples were collected and analyzed at different time points: at the baseline (T0), and $2 \mathrm{~h}$ (T1) and $4 \mathrm{~h}$ (T2) after inoculation. The adopted experimental design is summarized in Fig. 1. Microbiological and metataxonomic analysis were performed on PDHM and PM samples at baseline and on PDHM and IM samples at T1 and T2. Peptidomic analysis was conducted on the same samples except for T1.

\section{Subjects}


Mothers who delivered prematurely between November 2018 and January 2019 at the Neonatal Intensive Care Unit (NICU) of the Fondazione IRCCS Ca' Granda Ospedale Maggiore Policlinico (Milan, Italy), were included in the study. Eligible criteria were: delivery before the $37^{\text {th }}$ week of gestational age and absence of maternal antibiotic therapy at the time of the milk collection. Basic maternal and infants' clinical characteristics were collected using the computed medical records.

Term-delivering mothers, included in this study, donated their milk to the HMB of the Fondazione IRCCS Ca' Granda Ospedale Maggiore Policlinico, according to HMB Italian guidelines (13). Written informed consent was obtained for each participating mother. The study was approved by Ethical Committee of the Fondazione IRCCS Ca' Granda Ospedale Maggiore Policlinico (Approval nr. 289_2017).

\section{Preterm mother's own milk collection}

Preterm-delivering mothers, prior to milk collection, had to perform an accurate hand washing using a hand sanitizer and a breast washing, using exclusively running water, in accordance with the NICU internal procedure. Each sample was collected, using an electric breast pump of breastfeeding room and a personal breast pump kit, into a sterile bottle. Breast pump kit had to be cleaned and sterilized before every collection.

Enrolled preterm-delivering mothers collected a sample of $50 \mathrm{~mL}$ of their own fresh milk between the $30^{\text {th }}$ and the $60^{\text {th }}$ day post-delivery. All PM samples were collected during the first hours of the morning at the breastfeeding room of the NICU, immediately refrigerated and delivered to the laboratories for analyses. PM3 and PM5 samples were obtained from the same mother in different days.

\section{Donor HM collection and pasteurization}

Term delivering mothers, belonging to the HMB, collected their milk at home following the

the same instructions of mothers who delivered preterm, in terms of personal hygiene and material disinfection. Each sample was collected using an electric breast pump and a personal breast pump kit, and placed into sterile bottle. Breast pump kit had to be cleaned and sterilized before every collection.

Donor HM was stored at donors' home in a refrigerator for maximum $24 \mathrm{~h}$ and thereafter frozen at $-20^{\circ} \mathrm{C}$. During the transport, donor HM was preserved by maintaining the cold chain until the arriving to the HMB.

Donor HM samples, used to perform inoculation, were collected by donors in different periods of lactation. These samples were thawed, pooled (total volume of $3 \mathrm{~L}$ ) and then Holder pasteurized at 62.5 ${ }^{\circ} \mathrm{C}$ for 30 min. PDHM was stored at $-80^{\circ} \mathrm{C}$ until inoculation with fresh $\mathrm{PM}$ samples.

\section{Inoculation of PDHM with PM}

To perform the inoculation, frozen PDHM was gently thawed and $100 \mathrm{~mL}$ and inoculated with $10 \mathrm{~mL}$ of each fresh PM sample. The low milk volume expressed by preterm-delivering mothers, which necessarily 
must be used to breastfeed their babies, did not allow to consider higher inoculation level.

After inoculation, PDHM and IM samples were kept at $37^{\circ} \mathrm{C}$ for $4 \mathrm{~h}$ (incubation time).

PDHM and PM were analyzed immediately after their arrival in the laboratory. PDHM and IM samples were analyzed after incubation at different time points too, as described in the experimental design (Fig. 1).

\section{Enumeration of microorganisms}

Serial decimal dilutions of the inoculated aliquots in sterile quarter-strength Ringer's solution (Scharlab, Barcelona, Spain) were prepared, and the following microbiological determinations were carried out. Mesophilic aerobic bacteria were counted on Petrifilm Aerobic Count Plate (3M, Minneapolis, MN, USA) after incubation at $30^{\circ} \mathrm{C}$ for $72 \mathrm{~h}$ (ISO 4833-1:2013). Enterobacteriaceae were enumerated on Petrifilm Enterobacteriaceae Count Plate (3M) at $37^{\circ} \mathrm{C}$ for $24 \mathrm{~h}$ (ISO 21528-1:2017). Coliforms and Escherichia coli were determined on Petrifilm E. coli/Coliform Count Plate (3M) at $37^{\circ} \mathrm{C}$ for 24-48 h. De Man-RogosaSharpe (MRS) agar (Biolife Italiana, Milan, Italy), M17 agar (Biolife Italiana) and Kanamycin Aesculin Azide (KAA) agar (Scharlab) were used for the enumeration of rod-shaped lactic acid bacteria (LAB), cocci LAB (lactococci and streptococci) and enterococci, respectively. MRS agar was incubated at $37^{\circ} \mathrm{C}$ for 72 h under anaerobic conditions (AnaerocultA, Merck, Darmstad, Germany), while M17 and KAA agar were kept at $37^{\circ} \mathrm{C}$ for $48 \mathrm{~h}$. TOS-propionate agar (Sigma-Aldrich, St. Louis, MO, USA) with MUP selective supplement (Sigma-Aldrich) incubated at $37^{\circ} \mathrm{C}$ for $72 \mathrm{~h}$ under anaerobic conditions (AnaerocultA, Merck) was used to count Bifidobacterium spp. (14), whereas P2 agar (peptone, $5 \mathrm{~g}$; beef extract, $3 \mathrm{~g}$; yeast extract, $5 \mathrm{~g}$; sodium lactate, $1 \mathrm{~g}$; agar, $15 \mathrm{~g} / \mathrm{L}$ ) was used for anaerobic enumeration of Propionibacterium spp. Cultivating at $30^{\circ} \mathrm{C}$ for 7 days (15). Chloramphenicol Glucose Yeast Extract agar (Sacco Srl, Cadorago, Italy) after incubation at $25^{\circ} \mathrm{C}$ for 5 days was used to culture yeasts (16). Pseudomonas agar (Biolife Italiana) with PP Pseudomonas supplement (Biolife Italiana) kept at $30^{\circ} \mathrm{C}$ for $48 \mathrm{~h}$ (17) and Bacillus cereus agar base (PEMBA) agar (Biolife Italiana) with Bacillus cereus Antimicrobic Supplement (Biolife Italiana) incubated at $30^{\circ} \mathrm{C}$ for $24 \mathrm{~h}(18)$ were used for the detection of Pseudomonas spp. and Bacillus cereus, respectively. Baird Parker (BP) agar (Biolife Italiana) with RPF Supplement (Biolife Italiana) was used for coagulase-positive and negative staphylococci counting after incubation at $37{ }^{\circ} \mathrm{C}$ for $48 \mathrm{~h}$ (19). At any sampling time, PDHM sample was also analysed for detection of mesophilic aerobic bacteria, Enterobacteriaceae, coliforms, E. coli, yeasts, Pseudomonas spp., coagulase-positive and negative staphylococci and $B$. cereus.

\section{Search for Listeria monocytogenes and Pseudomonas aeruginosa}

Listeria monocytogenes was searched in all IM and PDHM samples by SureFast ${ }^{\circledR}$ Listeria monocytogenes PLUS real-time PCR (RT-PCR) assay (R-Biopharm, Darmstadt, Germany) according to the manufacturer's instructions. The RT-PCR amplification reactions were performed on an Eco Real-Time PCR System (Illumina, San Diego, CA, USA). Detection of Pseudomonas aeruginosa was performed in samples where the presence of Pseudomonas spp. had been detected by microbiological cultivation 
method. The adopted protocol was as follows: ten colonies from PP agar plates were randomly picked and sub-cultured overnight in Brain Heart Infusion (BHI) broth (Scharlab) at $30^{\circ} \mathrm{C}$. After growth, the DNA was extracted by the MicroLYSIS kit (Clent Life Science, Stourbridge, UK). The identification of isolates was carried out using $P$. aeruginosa specific primer as previously reported in Cremonesi et al. (20).

\section{Search for Staphylococcus aureus virulence and enterotoxin genes}

Staphylococcus aureus virulence and enterotoxin genes were explored in samples found to be contaminated with coagulase-positive staphylococci. The DNA was extracted from $1 \mathrm{~mL}$ of breast milk as previously described by Cremonesi et al. (21). The extracted DNA was amplified by a multiplex PCR for the detection of genes encoding for the coagulase (coa) and thermonuclease (nuc) regions and for the main staphylococcal enterotoxins (sea, sec, sed, seg, seh, sei, sej and sel) according to Cremonesi et al. (22).

\section{Metataxonomic analysis}

Five $\mathrm{mL}$ of milk sample were centrifuged at $500 \mathrm{~g}$ for $10 \mathrm{~min}$ at $4{ }^{\circ} \mathrm{C}$; the supernatant was discarded, and the pellet was washed with one $\mathrm{mL}$ of saline solution $(0.9 \% \mathrm{NaCl})$ and centrifuged at $500 \mathrm{~g}$ for $5 \mathrm{~min}$ at 4 ${ }^{\circ} \mathrm{C}$. The supernatant was discarded, and the bacterial DNA was extracted from the samples as described previously (23), by using a method based on the combination of a chaotropic agent, guanidium thiocyanate, with silica particles, to obtain bacterial cell lysis and nuclease inactivation. DNA quality and quantity were assessed using a NanoDrop ND-1000 spectrophotometer (NanoDrop Technologies, Wilmington, DE, USA). The isolated DNA was then stored at $-20{ }^{\circ} \mathrm{C}$ until use.

\section{Metagenomic library preparation and sequencing}

Bacterial DNA was amplified using the primers described by Caporaso et al. (24), which targeted the V3V4 hypervariable regions of the $16 \mathrm{~S}$ rRNA gene. All PCR amplifications were performed in $25 \mu \mathrm{L}$ volumes per sample. A total of $12.5 \mu \mathrm{L}$ of Phusion High-Fidelity Master Mix $2 \times$ (Thermo Fisher Scientific, Waltham, MA, USA) and $0.2 \mu \mathrm{L}$ of each primer $(100 \mu \mathrm{M})$ were added to $2 \mu \mathrm{L}$ of genomic DNA ( $5 \mathrm{ng} / \mu \mathrm{L})$. Amplification was performed in an Applied Biosystem 2700 thermal cycler (Thermo Fisher Scientific) using the amplification cycle as follows: samples were denatured at $98^{\circ} \mathrm{C}$ for $30 \mathrm{~s}$, followed by 25 cycles with a denaturing step at $98{ }^{\circ} \mathrm{C}$ for $30 \mathrm{~s}$, annealing at $56^{\circ} \mathrm{C}$ for $1 \mathrm{~min}$ and extension at $72^{\circ} \mathrm{C}$ for $1 \mathrm{~min}$, and a final extension at $72^{\circ} \mathrm{C}$ for 7 min. Amplicons were cleaned with Agencourt AMPure XP kit (Beckman Coulter, Brea, CA, USA) and libraries were prepared following the 16S Metagenomic Sequencing Library Preparation Protocol (Illumina, San Diego, CA, USA). The libraries obtained were quantified by RT-PCR with KAPA Library Quantification Kit (KapaBiosystems, Cape Town, South Africa), pooled in equimolar proportion and sequenced during a single MiSeq (Illumina) run with 2×250-base paired-end reads.

\section{Bioinformatics and Statistical analysis}

Demultiplexed paired-end reads from 16S rRNA-gene sequencing were first checked for quality using FastQC (25) for an initial assessment. Forward and reverse paired-end reads were joined into single reads 
using the C++ program SeqPrep (26). After joining, reads were filtered for quality based on: i) maximum three consecutive low-quality base calls (Phred < 19) allowed; ii) fraction of consecutive high-quality base calls (Phred > 19) in a read over total read length $\geq 0.75$; iii) no "N"-labeled bases (missing/uncalled) allowed. Reads that did not match all the above criteria were filtered out. All remaining reads were combined in a single FASTA file for the identification and quantification of OTUs (operational taxonomic units). Reads were aligned against the SILVA closed reference sequence collection release 123, with $97 \%$ cluster identity $(27 ; 28)$ applying the CD-HIT clustering algorithm (29). A pre-defined taxonomy map of reference sequences to taxonomies was then used for taxonomic identification along the main taxa ranks down to the genus level (domain, phylum, class, order, family, genus). By counting the abundance of each OTU, the OTU table was created and then grouped at each phylogenetic level. OTUs with total counts lower than 10 in fewer than 2 samples were filtered out. All of the above steps, except the FastQC reads quality check, were performed with the QIIME open-source bioinformatics pipeline for microbiome analysis (30).

The milk microbial diversity was assessed within- (alpha diversity) and across- (beta diversity) samples. All indices (alpha and beta diversity) were estimated from the complete OTU table (at the OTU level), filtered for OTUs with more than 10 total counts distributed in at least two samples. Besides the number of observed OTUs directly counted from the OTU table, within-sample microbial richness and diversity were estimated using the following indices: Chao1 and ACE (Abundance-based coverage Estimator) for richness, Shannon, Simpson and Fisher's alpha for diversity $(31 ; 32 ; 33 ; 34 ; 35 ; 36)$, Simpson E and Pielou's J (Shannon's evenness) for evenness (37). The across- sample milk microbiota diversity was quantified by calculating Bray-Curtis dissimilarities (38). Prior to the calculation of the Bray-Curtis dissimilarities, OTU counts were normalized for uneven sequencing depth by cumulative sum scaling CSS, (39). Among groups (PDHM, PM, IM) and pairwise Bray-Curtis dissimilarities at different timepoints were evaluated non-parametrically using the permutational analysis of variance approach (999 permutations; (40). Details on the calculation of the mentioned alpha- and beta-diversity indices can be found in Biscarini et al. (41).

Descriptive data related to clinical demographic data of preterm/term - delivering mothers and respective newborns, involved in this study, were reported as mean and standard deviation. Bacterial counts were expressed as mean and standard deviation and the significance level was set at 0.01 . Metataxonomic data were reported as mean and relative abundance (\%) and the significance level was set at 0.05 .

\section{Peptidomic profiling by UPLC/HR-MS/MS}

Peptidomic analyses were performed using an Acquity UPLC module (Waters, Milford, MA, USA) coupled to a Q Exactive hybrid quadrupole-Orbitrap mass spectrometer (Thermo Fisher Scientific, San Jose, CA, USA) and the peptides were identified using the Proteome Discoverer v1.4 software (Thermo Fisher Scientific). The MS data were processed, and the peptides were identified using the Proteome Discoverer v1.4 software (Thermo Fisher Scientific). Automatic peak detection was performed setting signal-to-noise ratio to 4 as suggested by Mangé et al. (42). The sequences of peptides were identified from MS/MS 
spectra using SequestHT algorithm (43) against a HM protein library constructed based on results from previous studies $(42 ; 44 ; 45 ; 46 ; 47)$. A non-specific enzyme cleavage pattern was defined, and 12 missed cleavage sites (maximum allowed for the algorithm) were allowed. No static modifications were set. Phosphorylation of serine and threonine, deamidation of asparagine, glutamine and arginine, oxidation of methionine and cyclisation of an N-terminal glutamine to pyro-glutamic acid were selected as dynamic modifications. Mass error tolerance for precursor ions was $5 \mathrm{ppm}$ and for fragment ions was $0.02 \mathrm{Da}$. A strict false discovery rate of peptide identification was set $(F D R=0.01)$.

\section{Results}

Nine preterm-delivering mothers were enrolled in the study and ten samples of fresh PM were collected (PM3 and PM5 were from the same mother) from November 2018 to January 2019. Clinical demographic data regarding mothers and respective newborns were reported in Table 1.

Table 1. Clinical demographic data regarding preterm-delivering mothers and respective newborns.

\begin{tabular}{|lllll|}
\hline Milk Sample & $\begin{array}{l}\text { Gestational Age } \\
\text { (week) }\end{array}$ & Birth Weight (g) & Maternal Age (years) & Parity \\
\hline PM1 & 36 & 2830 & 30 & Primipara \\
\hline PM2 & 35 & 2005 & 24 & Primipara \\
\hline PM3 & 31 & 1150 & 44 & Primipara \\
\hline PM4 & 28 & 810 & 47 & Multipara \\
\hline PM5 & 31 & 1150 & 44 & Primipara \\
\hline PM6 & 29 & 1480 & 35 & Primipara \\
\hline PM7 & 34 & 1660 & 33 & Multipara \\
\hline PM8 & 34 & 1450 & 33 & Primipara \\
\hline PM9 & 31 & 2050 & 26 & Primipara \\
\hline PM10 & 32 & 975 & 29 & Primipara \\
\hline
\end{tabular}

Four term-delivering mothers donated milk for this study in November 2018. Mean weight and gestational age at birth of their infants was $3160 \pm 970,8$ and 38,8 $\pm 1,3$ respectively. Main age of donors enrolled was $29.75 \pm 2.5$ and two of them were primiparae.

\section{Microbiological features of PDHM, PM and IM samples at different time points of incubation}

Total bacterial count (TBC) of PDHM did not change throughout the incubation with an average load of $2.56 \log _{10} \mathrm{CFU} / \mathrm{mL}$ which most probably included heat-resistant spore-forming bacteria. Total bacterial 
count of PM and IM samples is shown in Fig. 2.

A great variability was found among the PM samples, which presented a TBC ranging from 3.36 to 5.48 $\log _{10} \mathrm{CFU} / \mathrm{mL}$. Although exhibiting different growth evolution, IM samples at T2 showed a TBC not significantly different $(p>0.01)$ from those of PM samples used for inoculation of PDHM.

The pathogenic bacteria B. cereus, E. coli and L. monocytogenes were not detected. P. aeruginosa was revealed only in IM3, IM5 and IM7 samples at T2 (Table 2). In the same samples, S. aureus was found at all sampling times (data not shown), achieving at the end of incubation values comparable to those detected in the corresponding PM samples. Moreover, S. aureus strains harboring toxin genes (sea and seh) were detected in PM3, PM5 and IM3, IM5 samples. Coliforms and Enterobacteriaceae were present at similar level (about $2 \log _{10} \mathrm{CFU} / \mathrm{mL}$ ) in IM3 and IM5 samples, and the content of these microorganisms was about 1.5 log higher than in the corresponding PM samples (Table 2).

As for LAB, Lactobacillus spp. and Streptococcus spp. were recovered in many of the PM samples, while enterococci were found in PM4 and PM10. At T2, the corresponding IM samples showed LAB levels not significantly different $(p>0.01)$. The applied experimental conditions did not promote the growth of Propionibacteria, since their counts in the IM samples were generally 1 log lower than in the PM samples at T3. A similar trend was observed for Bifidobacterium and yeasts.

Table 2. Bacterial count of different species of microorganisms in PM and IM samples at T2. 


\begin{tabular}{|c|c|c|c|c|c|c|}
\hline Description & Genus/Species & Phylum & $\begin{array}{l}\log _{10} \\
\mathrm{CFU} / \mathrm{mL}\end{array}$ & Samples & & \\
\hline PM & IM & PM & IM & & & \\
\hline Pathogens & B. cereus & (Fir) & $<1.0$ & $<1.0$ & - & - \\
\hline E. coli & (Pro) & $<1.0$ & $<1.0$ & - & - & \\
\hline L. monocytogenes* & (Fir) & absent & absent & - & - & \\
\hline$P$. aeruginosa* & (Pro) & absent & present & - & $3,5,7$ & \\
\hline S. aureus & (Fir) & $\begin{array}{l}3.8 \pm \\
1.1\end{array}$ & $\begin{array}{l}4.0 \pm \\
1.3\end{array}$ & $3,5,6,7$ & $3,5,6,7$ & \\
\hline S. aureus toxin genes* & & sea-seh & sea-seh & 3,5 & 3,5 & \\
\hline Hygiene indicators & Coliforms & (Pro) & $2.4 \pm 0.8$ & $3.8 \pm 0.3$ & 3,5 & $\begin{array}{l}3, \\
5\end{array}$ \\
\hline Enterobacteriaceae & (Pro) & $\begin{array}{l}1.9 \\
\pm 1.3\end{array}$ & $\begin{array}{l}4.4 \pm \\
0.9\end{array}$ & 3,5 & 3,5 & \\
\hline Pseudomonas spp. & (Pro) & $\begin{array}{l}2.0 \\
\pm 1.1\end{array}$ & $\begin{array}{l}3.4 \pm \\
1.5\end{array}$ & 3,5 & $3,5,7$ & \\
\hline LAB & $\begin{array}{l}\text { Enterococcus } \\
\text { spp. }\end{array}$ & (Fir) & $\begin{array}{l}3.6 \pm \\
1.3\end{array}$ & $3.8 \pm 1.3$ & 4,10 & $\begin{array}{l}4 \\
10\end{array}$ \\
\hline Lactobacillus spp. & (Fir) & $\begin{array}{l}3.9 \pm \\
0.8\end{array}$ & $\begin{array}{l}3.3 \pm \\
1.3\end{array}$ & $\begin{array}{l}\text { all } \\
\text { samples }\end{array}$ & $\begin{array}{l}\text { all } \\
\text { samples }\end{array}$ & \\
\hline Streptococcus spp. & (Fir) & $\begin{array}{l}3.3 \pm \\
0.7\end{array}$ & $\begin{array}{l}3.1 \pm \\
1.8\end{array}$ & $\begin{array}{l}1,2,3,4 \\
8,9,10\end{array}$ & $\begin{array}{l}1,2,3,4 \\
8,10\end{array}$ & \\
\hline Other bacteria & $\begin{array}{l}\text { Bifidobacterium } \\
\text { spp. }\end{array}$ & (Act) & $\begin{array}{l}2.0 \pm \\
0.1\end{array}$ & absent & 9 & - \\
\hline Propionibacterium spp. & (Act) & $\begin{array}{l}3.2 \pm \\
0.7\end{array}$ & $\begin{array}{l}2.1 \pm \\
0.6\end{array}$ & $\begin{array}{l}1,2,3,4, \\
5,7\end{array}$ & $\begin{array}{l}1,2,3,4 \\
5,7\end{array}$ & \\
\hline Yeasts & & (Asc) & $\begin{array}{l}2.6 \pm \\
1.1\end{array}$ & $1.5 \pm 0.1$ & 5,9 & $\begin{array}{l}5, \\
9\end{array}$ \\
\hline
\end{tabular}

Data were expressed as mean \pm SD. 
Note.* detected by PCR or RT-

PCR. Fir: Firmicutes; Pro:

Proteobacteria; Act:

Actinobacteria; Asc:

Ascomycota

\section{Metataxonomics analysis of PDHM, PM and IM samples}

The microbiota structure of PDHM, PM, and IM samples produced a total of 8,971,219 reads. After quality filtering, 7,934,897 high quality reads were left, with a mean of 152,594 reads per sample (average loss 12.5\%). Microbial profiles were evaluated in PDHM and PM samples, and IM samples at different time points. Sequence-based rarefaction curves were obtained from the QIIME pipeline; the sample-based rarefaction curve was produced with ad hoc $\mathrm{R}$ functions. The observed number of OTUs detected was plotted as a function of the number of reads (up to 75,000) in each sample and of the number of samples (see Additional Figure 1). Both curves tend to plateau asymptotically suggesting that sampling and depth of coverage in this analysis were enough to describe the biological diversity of the maternal milk microbiome, although a few samples have been under-sequenced.

Results from 16S rRNA-gene sequencing from all samples have been used to characterize the core microbiome in PDHM, PM and IM samples. OTUs were grouped taxonomically at the phylum level. In terms of relative abundances, most of the reads for PDHM and IM samples belonged to the Proteobacteria and Firmicutes phyla (Fig. 2), which accounted for almost $100 \%$ of the entire microbiota at all time points (Table 3). Firmicutes (70\%), followed by Actinobacteria (16.1\%) and Proteobacteria (13.3\%) were the predominant phyla in PM samples. The metataxonomic analysis showed a different microbiota composition for the PDHM and IM samples versus the PM samples. In IM samples, at the latest timepoint (4h) Bacteroidetes and Cyanobacteria had a relative abundance lower than $1 \%$. Differences between PDHM and PM samples at T0 were significant for Actinobacteria ( $p$-value $=0.04)$, Firmicutes ( $p$ value $=0.04)$ and Proteobacteria ( $p$-value $=0.0006$ ).

Table 3. Average counts (and relative abundance) in PDHM, PM and IM samples per phylum and time point. 


\begin{tabular}{|lllll|}
\hline Phylum & Time point & PDHM & PM & IM \\
\hline Actinobacteria & T0 & $1424.67(0.7 \%)$ & $8716.2(16.1 \%)$ & \\
\hline Actinobacteria & T1 & $429(0.3 \%)$ & & $443.3(0.3 \%)$ \\
\hline Actinobacteria & T2 & $183(0.1 \%)$ & & $481.2(0.3 \%)$ \\
\hline Bacteroidetes & T0 & $88.67(0 \%)$ & $176.5(0.3 \%)$ & \\
\hline Bacteroidetes & T1 & $38(0 \%)$ & & $36.3(0 \%)$ \\
\hline Bacteroidetes & T2 & $26.33(0 \%)$ & & $35.9(0 \%)$ \\
\hline Cyanobacteria & T0 & $10.33(0 \%)$ & $106.2(0.2 \%)$ & $4.8(0 \%)$ \\
\hline Cyanobacteria & T1 & $2.67(0 \%)$ & & $5051.1(3 \%)$ \\
\hline Cyanobacteria & T2 & $2.33(0 \%)$ & & $14746(9.4 \%)$ \\
\hline Firmicutes & T0 & $6707(3.2 \%)$ & $37993.2(70 \%)$ & $164498.9(96.7 \%)$ \\
\hline Firmicutes & T1 & $4795(3 \%)$ & & $141243.9(90.2 \%)$ \\
\hline Firmicutes & T2 & $4066.67(3 \%)$ & & $7206(13.3 \%)$ \\
\hline Proteobacteria & T0 & $198125.33(96 \%)$ & & \\
\hline Proteobacteria & T1 & $153568.33(96.7 \%)$ & & \\
\hline Proteobacteria & T2 & $133308.67(96.9 \%)$ & & \\
\hline
\end{tabular}

Upon incubation, the microbial composition of PDHM remained mostly unchanged. After inoculation, Proteobacteria became the predominant phylum in IM samples (81-97\%), while Firmicutes moved from 3 $\%$ at T1 to $9.4 \%$ at T2 (Table 3). A complete list of the bacterial groups at phylum, family and genus level as well as their relative abundances are reported in Additional Table 1.

These data were further investigated in terms of the relative abundance in bacterial distribution, analyzing each PM sample and IM at T1 and T2 (Fig. 3). Differences in microbial composition between PDHM and PM samples found in the core microbiome analysis are shown in Fig. 4.

At the family level, the microbiota of the PM samples was characterized by Staphylococcaceae, with the prevalence of the genus Staphylococcus, and Bacillales with the prevalence of the genus Bacillus. Lactobacillales family members were observed in few PM samples, with low relative abundance. In PDHM sample, the class of Gammaproteobacteria and the Enterobacteriaceae family were the most predominant with Enterobacterales, Enterobacter and Escherichia-Shigella genus.

\section{Variation of different alpha-diversity and beta-diversity indices at different time points of incubation.}

The alpha-diversity indices were all significantly moving over time (Table 4). Between-group (PM vs PDHM; IM vs PDHM) differences were significant for the two evenness indices (equitability and Simpson's 
E), while the interaction between groups and time points was significant for the richness (Chao1, ACE, observed OTUs) and diversity (Fisher's alpha, Shannon) indices.

Table 4. Significance of differences between groups, time points and group-by-time point interactions for the measured alpha-diversity indices.

\begin{tabular}{|llll|}
\hline metric & group & timepoint & group:timepoint \\
\hline chao1 & 0.319267265573065 & 0.000165939790313 & 0.026149388877004 \\
\hline ace & 0.281827571210544 & 0.00015204377502 & 0.02149083957703 \\
\hline fisher_alpha & 0.394297272201391 & $5.47504683750568 \mathrm{E}-05$ & 0.011543626325129 \\
\hline observed_otus & 0.466686744320949 & 0.000141121189353 & 0.007350206565285 \\
\hline shannon & 0.530433049421532 & 0.000237520178032 & 0.006526211014198 \\
\hline equitability & 0.006789598291626 & $5.51219048916057 \mathrm{E}-05$ & 0.800258538626956 \\
\hline simpson_e & 0.003339694449603 & $4.41544751491096 \mathrm{E}-08$ & 0.048298187822701 \\
\hline
\end{tabular}

Fig. 5 shows the different alpha diversity indexes among samples and over time. For richness and diversity the highest values were consistently found for PDHM at T0: chao1 (891.357 compared to 569.463 of the PM samples), ACE (906.772 vs 567.161), Fisher's alpha (388.348 vs 248.361), observedOTUs (690.333 vs 4.966) and Shannon metrics (9.032 vs 8.639). For PDHM samples (highlighted in the right panel of Fig. 5), the alpha diversity was similar along the entire experimental period with values of $886.232,905.531,380.92,628.333$ and 8.855 at T3 for chao1, ace, fisher-alpha, observed OTUs and Shannon metrics, respectively.

On the contrary, for most IM samples there was an increment in microbial diversity four hours after the milk incubation at $37^{\circ} \mathrm{C}(\mathrm{T} 2)$, as reported by chao1 $(997,815$ vs 569,463$)$, ACE $(1016,157$ vs 567,161$)$, Fisher's alpha $(445,411$ vs 248,361$)$ and Shannon $(9,099$ vs 8,639$)$ metrics.

Beta-diversity analysis was evaluated with (Fig. 6A) and without (Fig. 6B) the PDHM sample. From PERMANOVA (999 permutations), the analysis showed a statistically significant $(p=0.001)$ separation between timepoints and hence between PM and IM samples, revealing major differences in the principal constituents of the microbial community (Fig. 6B). PDHM presented a different microbial community as compared to the PM (Fig. 6A) samples, and, being the substrate for the inoculum, its microbial composition was predominant within 4 hours of incubation.

\section{Peptidomic analysis of PDHM, PM and IM samples.}

A qualitative peptidomic analysis was conducted on PDHM, PM and IM samples at different time points. Since PM3 and PM5 were collected from the same mother and their peptidomic profiles overlapped, only the PM5 was considered for the discussion. In PM samples, about 800 unique peptides were identified. 
Each PM contained a different number of peptides, higher (PM1, PM2, PM4, PM7, PM10) or lower (PM5, PM6, PM8, PM9) than PDHM. As shown in Fig. 7, PM7 and PM10 appeared as the most proteolyzed samples, whereas the lowest extent of proteolysis characterized PM 5, 8 and 9 . About $60 \%$ of total peptides identified in PDHM and PM at T0 were of a molecular weight range between 1 and $3 \mathrm{kDa}$, while those smaller than $1 \mathrm{kD}$ a represented only $3 \%$ of total peptides (Fig. 7A). Human $\beta$-casein was the most representative protein with $62 \%$ of total peptides, followed by $a_{S 1}$-casein $(13 \%)$, osteopontin $(10 \%)$ and polymeric immunoglobulin receptor (6\%) (Fig. 7B). Peptides belonging to a-lactalbumin, one of the most abundant proteins in HM, were not found. At T2, the number and type of peptides in PDHM sample roughly overlapped those revealed at $\mathrm{TO}$. As a matter of fact, incubation for $4 \mathrm{~h}$ at $37^{\circ} \mathrm{C}$ did not alter the peptidomic profiles of PDHM sample. The peptidomic profile of IM samples, except for IM5 and IM6, resembled that of PDHM incubated for the same time (Fig. 7C and Fig. 7D). These results reflected in very similar patterns the precursor proteins for the peptide identified in IM samples at the end of incubation (T2) (Fig. 7D). The dominance of $\beta$-casein derived peptides (74\% of total peptides identified at T2) was confirmed in all IM samples. Peptides in the molecular weight range of $1-3 \mathrm{kD}$ a were still the most abundant (Fig. 7C).

\section{Discussion}

In this study, the effect of PM inoculation in PDHM on bacterial growth, HM microbiome diversity and proteolytic phenomena was evaluated. Several studies $(48 ; 49)$ showed that HM is not sterile and contains a variety of mother-specific probiotic and commensal bacteria, which constitute HM microbiome, a source of potential beneficial bacteria for the colonization of preterm infants' gut. The present study is one of the few investigations on the microbiome and peptidome of PDHM, PM and of the derived IM samples, and the first one dealing with the occurrence and potential growth of pathogenic bacteria in PM and related IM incubated samples.

The origin of bacteria in HM depends on different factors. Currently it is possible to distinguish between a "maternal microbiota" and an "exogenous microbiota", as supported by Moossavi \& Azad (50). Beyond the transfer of microbes from breast skin flora to the milk, other pathways are considered relevant to shape a specific HM microbiome among which contamination related to milk handling.

A recent review of Fernández \& Rodríguez confirmed that a bacterial load of HM from healthy women, collected hygienically, usually was about $3 \log _{10} \mathrm{CFU} / \mathrm{mL}$ while a bacterial load up to $6 \log _{10} \mathrm{CFU} / \mathrm{mL}$ was characteristic of mastitis suffering women or milk after breast pumping (51). Despite the adherence to hygienic condition in the Neonatal Intensive Care Unit, the bacterial load of our PM samples ranged from 3 to $5 \log _{10} \mathrm{CFU} / \mathrm{mL}$ that didn't exclude an external contamination of expressed HM during breast milk collection. Our results show that the inoculation of PDHM with PM $(10 \%, \mathrm{v} / \mathrm{v})$ allowed the restoration of a bacterial load samples similar to that of PM samples after 4 hours of incubation at $37^{\circ} \mathrm{C}$, although an high variability of bacterial growth between PM samples and then in IM samples was detected.

Anyway, all microorganisms grown in PM samples were found in the respective IM samples at T2. 
Specifically, in this study, cultivable bacteria as LAB or belonging to Staphylococcaceae, Streptococcaceae, Enterobacteriaceae and Pseudomonaceae and other gram-positive bacteria (Propionibacterium and Bifidobacterium) were detected in PM samples and in their related IM samples.

Most of the species belonging to the genera Lactobacillus and Bifidobacterium, commonly considered probiotic bacteria, can confer health benefits to HM-fed premature infants. LAB were found in all PM samples, were not found in PDHM but reached the same load in all IM samples at the end of incubation period. Some species of lactobacilli, commonly present in human breast milk, colonize the neonatal gut and contribute to protection against infant infections, suggesting that lactobacilli could potentially wellmodulate immunity (52). In gastrointestinal tract, HM lactobacilli strains are metabolically active in the infant gut and increase the production of functional metabolites such as butyrate, which is the main energy source for colonocytes and a relevant compound in the modulation of intestinal function (53).

Concerning Bifidobacteria, PM contains lower levels compared to milk of term-delivering mothers (54). Moreover, indirect breastfeeding could affect the concentration of Bifidobacteria in HM, which can be further lowered by the need to use breast-pump (2). In addition, Bifidobacteria grow only in strict anaerobic condition. This could explain our difficult to detect Bifidobacteria in PM and IM samples using traditional plate count method, as confirmed also by Boix-Amorós et al. (55).

The presence of microbial families belonged to Staphylococcaceae, Streptococcaceae, Enterobacteriaceae and Pseudomonaceae could be consistent with contamination during breast milk collection, even if hygienic protocols are used $(2 ; 56 ; 57)$.

Given that pasteurization of mother's own milk is not recommended (58), also potential pathogenic microorganisms are normally conveyed to preterm infants fed with fresh HM. Nevertheless, breastfeeding is recommended because the potential benefits of breast milk outweigh the possible negative effects: only few articles reported that neonatal infection was caused by the ingestion of contaminated HM (59).

The feeding of HM to the newborn should be avoided or stopped only in specific circumstances (60) and the implementation of the hygienic measures during milk collection, both in the Neonatal Intensive Care Unit and at home, could avoid proliferation of undesirable bacteria in expressed HM.

Holder pasteurization is necessary to neutralize pathogens potentially present in donor HM but unfortunately it reduce initial microbial load, destroying beneficial bacteria, as LAB and bifidobacteria (61). In our study, metataxonomic analysis underlined that the addition of a small amount of fresh HM can enhance the microbiome of PDHM, making it more similar to HM microbiome.

In accordance with other studies $(3 ; 62)$, the microbiome of our PM samples was mostly characterized by the presence of Staphylococcaceae, with the prevalence of the Staphylococcus genus, and Bacillales with the prevalence of the Bacillus genus. The large number of Firmicutes in these samples could be due to the presence on areolar skin of bacteria belonging to this phylum. 
Conversely, microbiome of our PDHM samples was mostly characterized by Proteobacteria, the dominant phylum in HM as also confirmed by Pannaraj et al. (62).

After inoculation and incubation, the microbiome of IM became richer of Firmicutes, predominant phylum of our PM samples. Therefore, Staphylococcaceae and Bacillales, found in IM samples at T2, make PDHM more similar to mother's own milk.

In addition, an increment in microbial diversity in IM samples four hours after the milk incubation was detected.

Fehr et al. demonstrated that the microbiota of milk and infants gut of mother-infants dyads are dissimilar but related (63). Milk and infants' gut microbiota become slightly more similar over time, sharing specific microbial strains, in association with breastfeeding mode and duration.

Preterm infants present a marked vulnerability to dysbiosis with a change in abundance, diversity, and progressive acquisition of the intestinal microbiota. Disrupted maturation of the intestinal microbiota occurred in extremely preterm infants with postnatal growth failure (64).

In the last years, metagenomics analysis underlined that HM microbiome modulate preterm infants' gut microbiota but, to the best of our knowledge, studies on the impact of different nutritional approaches on the gut microbiota of preterm infants are very limited.

Some studies $(5 ; 65 ; 66 ; 67)$ suggest that donor HM favors an intestinal microbial profile more similar to mother's own milk. On the other hands, the diversity of gut microbiota increased over time and was constantly higher in infants fed with mother's own milk relative to infants who was fed with donor or formula milk.

Ford et al. demonstrated that preterm infants fed with mother's own milk developed an increased gut microbial community compared to preterm infants fed with PDHM. In addition, infants fed mother's own milk had a better weigh gain and an improved feeding tolerance than donor HM-fed infants (66).

The inoculation strategy could personalize PDHM which could shape infants' gut microbiota increasing microbial diversity and promoting healthier short and long-term outcomes in preterm infants. In addition, increasing volume of own mother milk for inoculation could be more useful.

As described by Fernández et al. (53) HM bacteria have a remarkable potential metabolic roles in the infant and might also contribute to infant digestion through the breakdown of sugars and proteins. A recent study about metabolomics profile of donor HM identified several compounds as a result of microbial activity (68). Despite these results, the peptidomic profile of PDHM was slightly affected by incubation in this study, probably because it was previously stored at $-20^{\circ} \mathrm{C}$ and then pasteurized. As demonstrated by Ahrabi et al. (69), freezer storage of donor $\mathrm{HM}$ at $-20^{\circ} \mathrm{C}$ is associated with a decreasing bacterial count. It is also known that the Holder pasteurization process reduced the bacterial count and inactivated most of the bacterial and endogenous proteolytic enzymes $(70 ; 71)$. 
Each PM sample presented different degree of proteolysis that reflected in characteristic peptidomic profiles. Despite this inter-variability, negligible differences in proteolysis level and peptidomic profile among IM samples were detected over time. Overall, these features mostly reflected those of PDHM sample after the same time of incubation, thus underlying a minor additional exogenous proteolysis. The largest number of peptides in PDHM and PM samples derived from $\beta$-casein and, therefore, the same applied for IM samples. Different authors demonstrated the prevalence of $\beta$-casein derived peptides in HM $(72 ; 73 ; 74)$. Scarce presence of peptides derived from major whey protein, in particular from alactalbumin, characterized the studied samples, as reported for HM by Gan et al. (75).

\section{Conclusions}

The present research study revealed an inter-individual microbiological variability in fresh PM samples thus underlying that each preterm mother presents a unique fingerprint-like microbiota, which can be potentially delivered to own infant. The inter-individual variability of PM samples also reflected in their peptidomic profiles. In addition, the study demonstrated that inoculation with fresh PM partially restore and personalize HM microbiome of PDHM. This effect could be beneficial thanks to the presence of maternal probiotic bacteria which make PDHM more similar to mother's own milk. Nevertheless, the adoption and respect of strict hygienic measures during collection and storage of PM is paramount to avoid contamination of inoculated milk. Overall, the feasibility of inoculating PDHM with fresh PM for preterm infant feeding needs further investigation. In this view, the enlargement of the sample size of PM samples could reinforce the reliability of the results reducing variability and bias.

\section{Declarations}

\section{Authors' contributions}

DM contributed to the study concept, data interpretation and wrote the manuscript. CT contributed to the discussion of the results and the revision of the article. PP conceptualized and designed the protocol and reviewed the manuscript. SM, TS, FB, PC, BC, VP and MS carried out the analyses, collected data and wrote the manuscript. ID contributed to the study concept, data interpretation and critically reviewed the manuscript. OA and NL contributed to the discussion of the results and critically reviewed the manuscript. FM provided suggestions with regard to the content and concept of the article. PR conceptualized and designed the protocol and critically reviewed the manuscript. All authors red and approved the final manuscript.

\section{Acknowledgements}

The authors like to thank all mothers that decided to contribute to this study donating their milk.

\section{Competing interests}

The authors declare that they have no competing interests. 
Availability of data and supporting materials

The authors confirm that the data supporting the findings of this study are available within the article upon reasonable request.

\section{Ethics approval and consent to participate}

Protocol was approved by the institutional Ethics Committee of the Fondazione IRCCS Ca' Granda Ospedale Maggiore Policlinico, Milan (reference number = 289_2017). Informed written consent was obtained from all participants before enrollment.

\section{Funding}

No funding was secured for this study.

\section{Consent for publication}

Not applicable.

\section{Abbreviations}

HM, human milk; PDHM, pasteurized donor human milk; PM, preterm mother's own milk; IM, Inoculated milk (PDHM inoculated with PM); NICU, Neonatal Intensive Care Unit; LAB, Lactic acid bacteria.

\section{References}

1. Cheng L, Akkerman R, Kong C, Walvoort MTC, de Vos P. More than sugar in the milk: human milk oligosaccharides as essential bioactive molecules in breast milk and current insight in beneficial effects. Crit Rev Food Sci Nutr. 2020;0(0):1-17. Available from: https://doi.org/10.1080/10408398.2020.1754756

2. Moossavi S, Sepehri S, Robertson B, Bode L, Goruk S, Field CJ, et al. Composition and Variation of the Human Milk Microbiota Are Influenced by Maternal and Early-Life Factors. Cell Host Microbe. 2019;25(2):324-335.e4. Available from: https://doi.org/10.1016/j.chom.2019.01.011

3. Gomez-Gallego C, Garcia-Mantrana I, Salminen S, Collado MC. The human milk microbiome and factors influencing its composition and activity. Semin Fetal Neonatal Med. 2016;21(6):400-5. Available from: http://dx.doi.org/10.1016/j.siny.2016.05.003

4. Cacho NT, Harrison NA, Parker LA, Padgett KA, Lemas DJ, Marcial GE, et al. Personalization of the microbiota of donor human milk with mother's own milk. Front Microbiol. 2017;8(AUG):1-12.

5. Cong X, Genomics S, Judge M, Xu W, Diallo A, Janton S, et al. Influence of Infant Feeding Type on Gut Microbiome Development in Hospitalized Preterm Infants. Nurs Res. 2017;66(2):123-33.

6. Wilson E, Edstedt Bonamy AK, Bonet M, Toome L, Rodrigues C, Howell EA, et al. Room for improvement in breast milk feeding after very preterm birth in Europe: Results from the EPICE cohort. 
Matern Child Nutr. 2018;14(1):1-11.

7. Eidelman Al, Schanler RJ. Breastfeeding and the use of human milk. Pediatrics. 2012;129(3).

8. Human Milk Banking Association of North America. Best Practice for Expressing, Storing and Handling Human Milk in Hospitals, Homes, and Child Care Settings. HMBANA. 4th Edition 2019. Available online: https://www.hmbana.org/our-work/publications.html

9. Weaver G, Bertino E, Gebauer C, Grovslien A, Mileusnic-Milenovic R, Arslanoglu S, et al. Recommendations for the establishment and operation of Human Milk Banks in Europe: A consensus statement from the European Milk Bank Association (EMBA). Front Pediatr. 2019;7(MAR):1-8.

10. Cacho NT, Lawrence RM. Innate immunity and breast milk. Front Immunol. 2017;8(MAY).

11. Beghetti I, Biagi E, Martini S, Brigidi P, Corvaglia L, Aceti A. Human milk's hidden gift: Implications of the milk microbiome for preterm infants' health. Nutrients. 2019;11(12):1-13

12. Zhu J, Dingess KA. The functional power of the human milk proteome. Nutrients. 2019;11(8):1-27.

13. Arslanoglu S, Bertino E, Tonetto P, De Nisi G, Ambruzzi AM, Biasini A, et al. Guidelines for the establishment and operation of a donor human milk bank. J Matern Neonatal Med. 2010;23(SUPPL. 2):1-20.

14. ISO 21527-1:2008: Microbiology of food and animal feeding stuffs - Horizontal method for the enumeration of yeasts and moulds Colony count technique in products with water activity greater than 0,95

15. Zucali M, Bava L, Colombini S, Brasca M, Decimo M, Morandi S, et al. Management practices and forage quality affecting the contamination of milk with anaerobic spore-forming bacteria. J Sci Food Agric. 2015;95(6):1294-302.

16. ISO 29981:2010: Milk products - Enumeration of presumptive bifidobacteria - Colony count technique at 37 degrees $\mathrm{C}$

17. ISO/TS 11059:2009: Milk and milk products - Method for the enumeration of Pseudomonas spp.

18. ISO 21871:2006: Microbiology of food and animal feeding stuffs - Horizontal method for the determination of low numbers of presumptive Bacillus cereus - Most probable number technique and detection method.

19. ISO/NP 6888-3:2003: Microbiology of food and animal feeding stuffs - Horizontal method for the enumeration of coagulase-positive staphylococci (Staphylococcus aureus and other species) - Part 3: Detection and MPN technique for low numbers.

20. Cremonesi P, Pisani LF, Lecchi C, Ceciliani F, Martino P, Bonastre AS, et al. Development of 23 individual TaqMan $®$ real-time PCR assays for identifying common foodborne pathogens using a single set of amplification conditions. Food Microbiol. 2014;43:35-40. Available from: http://dx.doi.org/10.1016/j.fm.2014.04.007

21. Cremonesi P, Perez G, Pisoni G, Moroni P, Morandi S, Luzzana M, et al. Detection of enterotoxigenic Staphylococcus aureus isolates in raw milk cheese. Lett Appl Microbiol. 2007;45(6):586-91 
22. Cremonesi P, Luzzana M, Brasca M, Morandi S, Lodi R, Vimercati C, et al. Development of a multiplex PCR assay for the identification of Staphylococcus aureus enterotoxigenic strains isolated from milk and dairy products. Mol Cell Probes. 2005;19(5):299-305.

23. Cremonesi P, Ceccarani C, Curone G, Severgnini M, Pollera C, Bronzo V, et al. Milk microbiome diversity and bacterial group prevalence in a comparison between healthy holstein friesian and rendena cows. PLoS One. 2018;13(10):1-17.

24. Caporaso JG, Lauber CL, Walters WA, Berg-Lyons D, Lozupone CA, Turnbaugh PJ, et al. Global patterns of 16S rRNA diversity at a depth of millions of sequences per sample. Proc Natl Acad Sci U S A. 2011;108(SUPPL. 1):4516-22.

25. Andrews S. FastQC: A Quality Control Tool for High Throughput Sequence Data. 2010. Available online at: http://www.bioinformatics.babraham.ac.uk/projects/fastqc/

26. John JA. SeqPrep v1.1 - Tool for stripping adaptors and/or merging paired reads with overlap into single reads. 2011. Available from:https://github.com/jstjohn/SeqPrep

27. Quast C, Pruesse E, Yilmaz P, Gerken J, Schweer T, Yarza P, et al. The SILVA ribosomal RNA gene database project: Improved data processing and web-based tools. Nucleic Acids Res. 2013;41(D1):590-6.

28. Yilmaz P, Parfrey LW, Yarza P, Gerken J, Pruesse E, Quast C, et al. The SILVA and "all-species Living Tree Project (LTP)" taxonomic frameworks. Nucleic Acids Res. 2014;42(D1):643-8.

29. Weizhong L, Godzik A. Cd-hit: a fast program for clustering and comparing large sets of protein or nucleotide sequences. Bioinformatics. 2006; 22(13):1658-9. doi: 10.1093/bioinformatics/btl158.

30. Caporaso JG ,Kuczynski J, Stombaugh J, Bittinger K, Bushman FD, Costello EK et al. QIIME allowsanalysis of high-throughput community sequencing data. Nature. 2010;7:335336.doi:10.1038/nmeth.f.303.

31. Chao A. Nonparametric estimation of the number of classes in a population author. Scan J Stat. $1984 ; 11: 265-70$.

32. Chao A, Lee SM. Estimating the number of classes via sample coverage. J Am Stat Assoc. 1992; 87:210. doi: 10.1080/01621459.1992.10475194

33. Chao A, Ma MC, Yang MCK. Stopping rule and estimation for recapture debugging with unequal detection rates. Biometrika.1993; 80:193-201. doi: 10.1093/biomet/80.1.193

34. Shannon C. A mathematical theory of communication, the bell system technical journal. Bell Syst Techn J. 1948; 379-427. doi: 10.1002/j.1538-7305.1948.tb01338.x

35. Simpson EH. Measurement of diversity [16]. Vol. 163, Nature. 1949. p. 688.

36. Fisher RA, Corbet AS, Williams CB. The Relation Between the Number of Species and the Number of Individuals in a Random Sample of an Animal Population. The Journal of Animal Ecology. 1943; 12(1), 42. https://doi.org/10.2307/1411

37. Smith B, Wilson JB. A Consumer's Guide to Evenness Indices. Oikos. 1996;76(1), 70. https://doi.org/10.2307/3545749 
38. Bray JR, Curtis JT. An Ordination of the Upland Forest Communities of Southern Wisconsin. Ecological Monographs. 1957;27(4), 325-349. https://doi.org/10.2307/1942268

39. Paulson JN, Colin Stine O, Bravo HC, Pop M. Differential abundance analysis for microbial markergene surveys. Nature Methods, 2013; 10(12), 1200-1202. https://doi.org/10.1038/nmeth.2658

40. Anderson M. A new method for non-parametric multivariate analysis of variance. Austr Ecol. 2001; 26:32-46. doi: 10.1046/j.1442-9993.2001. 01070.x

41. Biscarini F, Palazzo F, Castellani F, Masetti G, Grotta L, Cichelli A, et al. Rumen microbiome in dairy calves fed copper and grape-pomace dietary supplementations: Composition and predicted functional profile. PLoS One. 2018;13(11):1-20.

42. Mangé A, Bellet V, Tuaillon E, Van de Perre P, Solassol J. Comprehensive proteomic analysis of the human milk proteome: Contribution of protein fractionation. J Chromatogr B Anal Technol Biomed Life Sci. 2008;876(2):252-6.

43. Tabb DL. The SEQUEST Family Tree. J Am Soc Mass Spectrom. 2015;26(11):1814-9.

44. Pica V, Stuknytė M, Masotti F, De Noni I, Cattaneo S. Bovine milk fortifiers and fortified pasteurized donor human milk for premature infant nutrition. Peptidomic overview. Lwt. 2021;135(June 2020)

45. Liao Y, Alvarado R, Phinney B, Lönnerdal B. Proteomic Characterization of Human Milk Fat Globule Membrane Proteins during a 12 Month Lactation Period. Proteome Res, 2011; 10(8): 3530-41. doi: $10.1021 / \mathrm{pr} 200149 \mathrm{t}$

46. Lönnerdal B. Nutritional and physiologic significance of human milk proteins. Am J Clin Nutr. 2003;77(6)

47. Molinari CE, Casadio YS, Hartmann BT, Livk A, Bringans S, Arthur PG, et al. Proteome mapping of human skim milk proteins in term and preterm milk. J Proteome Res. 2012;11(3):1696-714.

48. Lyons KE, Ryan CA, Dempsey EM, Ross RP, Stanton C. Breast milk, a source of beneficial microbes and associated benefits for infant health. Nutrients. 2020;12(4):1-30.

49. Stinson LF, Sindi ASM, Cheema AS, Lai CT, Mühlhäusler BS, Wlodek ME, et al. The human milk microbiome: who, what, when, where, why, and how? Nutr Rev. 2020;0(0):1-18.

50. Moossavi S, Azad MB. Origins of human milk microbiota: new evidence and arising questions. Gut Microbes. 2020;12(1):1667722. Available from: https://doi.org/10.1080/19490976.2019.1667722

51. Fernández L, Rodríguez JM. Human Milk Microbiota: Origin and Potential Uses. Nestle Nutr Inst Workshop Ser. 2020;94:75-85.

52. Pérez-Cano FJ, Dong H, Yaqoob P. In vitro immunomodulatory activity of Lactobacillus fermentum CECT5716 and Lactobacillus salivarius CECT5713: two probiotic strains isolated from human breast milk. Immunobiology. 2010;215(12):996-1004

53. Fernández L, Langa S, Martín V, Maldonado A, Jiménez E, Martín R, et al. The human milk microbiota: Origin and potential roles in health and disease. Pharmacol Res [Internet]. 2013;69(1):1-10. Available from: http://dx.doi.org/10.1016/j.phrs.2012.09.001 
54. Khodayar-Pardo P, Mira-Pascual L, Collado MC, Martínez-Costa C. Impact of lactation stage, gestational age and mode of delivery on breast milk microbiota. J Perinatol. 2014;34(8):599-605.

55. Boix-Amorós A, Collado MC, Mira A. Relationship between milk microbiota, bacterial load, macronutrients, and human cells during lactation. Front Microbiol. 2016;7(APR):1-9.

56. Jiménez E, Arroyo R, Cárdenas N, Marín M, Serrano P, Fernández L, et al. Mammary candidiasis: A medical condition without scientific evidence? PLoS One. 2017;12(7).

57. Sakwinska O, Moine D, Delley M, Combremont S, Rezzonico E, Descombes P, et al. Microbiota in breast milk of Chinese lactating mothers. PLoS One. 2016;11(8):1-14.

58. Vincent M, Ménard O, Etienne J, Ossemond J, Durand A, Buffin R, et al. Human milk pasteurisation reduces pre-lipolysis but not digestive lipolysis and moderately decreases intestinal lipid uptake in a combination of preterm infant in vitro models. Food Chem [Internet]. 2020;329(April):126927. Available from: https://doi.org/10.1016/j.foodchem.2020.126927

59. Widger J, O'Connell NH, Stack T. Breast milk causing neonatal sepsis and death. Clin Microbiol Infect [Internet]. 2010;16(12):1796-8. Available from: http://dx.doi.org/10.1111/j.1469-0691.2010.03071.x

60. Civardi E, Garofoli F, Tzialla C, Paolillo P, Bollani L, Stronati M. Microorganisms in human milk: Lights and shadows. J Matern Neonatal Med. 2013;26(SUPPL.2):30-4.

61. Fernández L, Ruiz L, Jara J, Orgaz B, Rodríguez JM. Strategies for the preservation, restoration and modulation of the human milk microbiota. Implications for human milk banks and neonatal intensive care units. Front Microbiol. 2018;9(NOV):1-13.

62. Pannaraj PS, Li F, Cerini C, Bender JM, Yang S, Rollie A, et al. Association between breast milk bacterial communities and establishment and development of the infant gut microbiome. JAMA Pediatr. 2017;171(7):647-54.

63. Fehr K, Moossavi S, Sbihi H, Boutin RCT, Bode L, Robertson B, et al. Breastmilk Feeding Practices Are Associated with the Co-Occurrence of Bacteria in Mothers' Milk and the Infant Gut: the CHILD Cohort Study. Cell Host Microbe. 2020;28(2):285-297.e4.

64. Younge NE, Newgard CB, Cotten CM, Goldberg RN, Muehlbauer MJ, Bain JR, et al. Disrupted Maturation of the Microbiota and Metabolome among Extremely Preterm Infants with Postnatal Growth Failure. Sci Rep. 2019;9(1):1-12.

65. Parra-Llorca A, Gormaz M, Alcántara C, Cernada M, Nuñez-Ramiro A, Vento M, et al. Preterm gut microbiome depending on feeding type: Significance of donor human milk. Front Microbiol. 2018;9(JUN):1-10.

66. Ford SL, Lohmann P, Preidis GA, Gordon PS, O’Donnell A, Hagan J, et al. Improved feeding tolerance and growth are linked to increased gut microbial community diversity in very-low-birth-weight infants fed mother's own milk compared with donor breast milk. Am J Clin Nutr. 2019;109(4):1088-97.

67. Morais J, Marques C, Teixeira D, Durão C, Faria A, Brito S et al. FEEDMI: A Study Protocol to Determine the Influence of Infant-Feeding on Very-Preterm-Infant's Gut Microbiota. Neonatology. 2019;116(2):179-184. doi: 10.1159/000496547. 
68. Torrez Lamberti MF, DeBose-Scarlett E, Garret T, Parker LA, Neu J, Lorca GL. Metabolomic Profile of Personalized Donor Human Milk. Molecules. 2020;25(24).

69. Ahrabi AF, Handa D, Codipilly CN, Shah S, Williams JE, McGuire MA, et al. Effects of Extended Freezer Storage on the Integrity of Human Milk. J Pediatr [Internet]. 2016;177:140-3. Available from: http://dx.doi.org/10.1016/j.jpeds.2016.06.024

70. Wesolowska A, Sinkiewicz-Darol E, Barbarska O, Bernatowicz-Lojko U, Borszewska-Kornacka MK, van Goudoever JB. Innovative techniques of processing human milk to preserve key components. Nutrients. 2019;11(5):1-17.

71. Paulaviciene IJ, Liubsys A, Eidukaite A, Molyte A, Tamuliene L, Usonis V. The Effect of Prolonged Freezing and Holder Pasteurization on the Macronutrient and Bioactive Protein Compositions of Human Milk. Breastfeed Med. 2020;15(9):583-8.

72. Deglaire A, Oliveira S De, Jardin J, Briard-Bion V, Kroell F, Emily M, et al. Impact of human milk pasteurization on the kinetics of peptide release during in vitro dynamic digestion at the preterm newborn stage. Food Chem [Internet]. 2019;281(December 2018):294-303. Available from: https://doi.org/10.1016/j.foodchem.2018.12.086

73. Dallas DC, Guerrero A, Khaldi N, Borghese R, Bhandari A, Underwood MA, et al. A peptidomic analysis of human milk digestion in the infant stomach reveals protein-specific degradation patterns. $J$ Nutr. 2014;144(6):815-20.

74. Wada Y, Lönnerdal B. Bioactive peptides released from in vitro digestion of human milk with or without pasteurization. Pediatr Res. 2015;77(4):546-53.

75. Gan J, Robinson RC, Wang J, Krishnakumar N, Manning CJ, Lor Y, et al. Peptidomic profiling of human milk with LC-MS/MS reveals $\mathrm{pH}$-specific proteolysis of milk proteins. Food Chem. 2019;274(March 2018):766-74.

\section{Figures}


T0: baseline

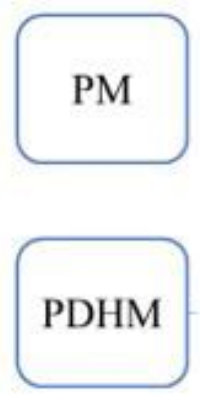

- Microbiological analysis

- Metataxonomic analysis

- Peptidomic analysis

* Time of incubation at $37^{\circ} \mathrm{c}$
T1: $2 h^{*}$

T2: $4 h^{*}$

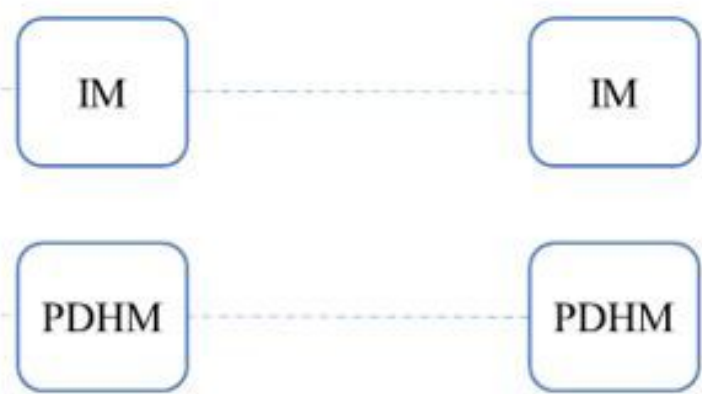

- Microbiological analysis

- Metataxonomic analysis
- Microbiological analysis

- Metatyaxonomic analysis

- Peptidomic analysis

Figure 1

Experimental design of the study.

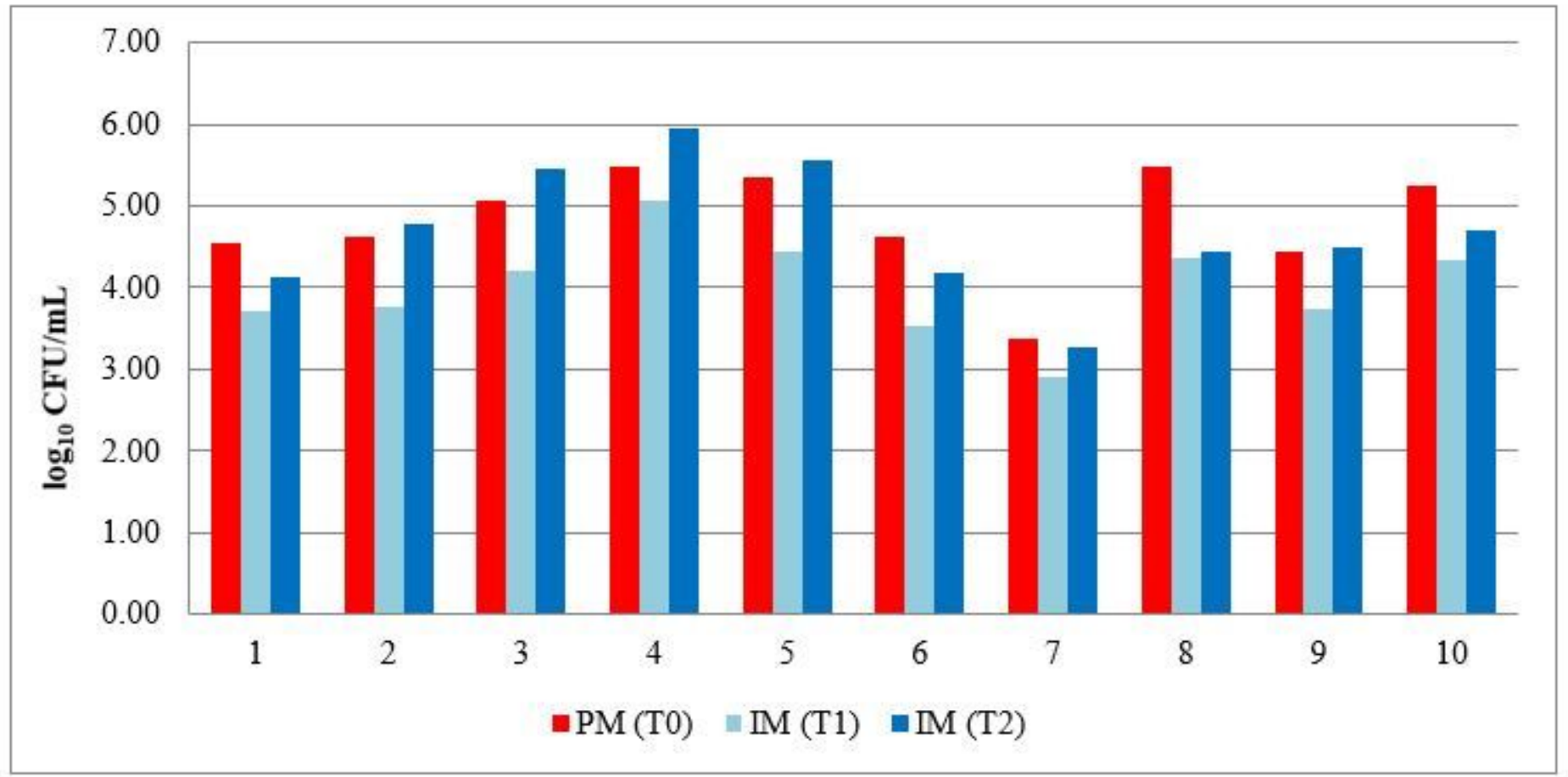

Figure 2

Total bacterial count of PM and IM samples. 


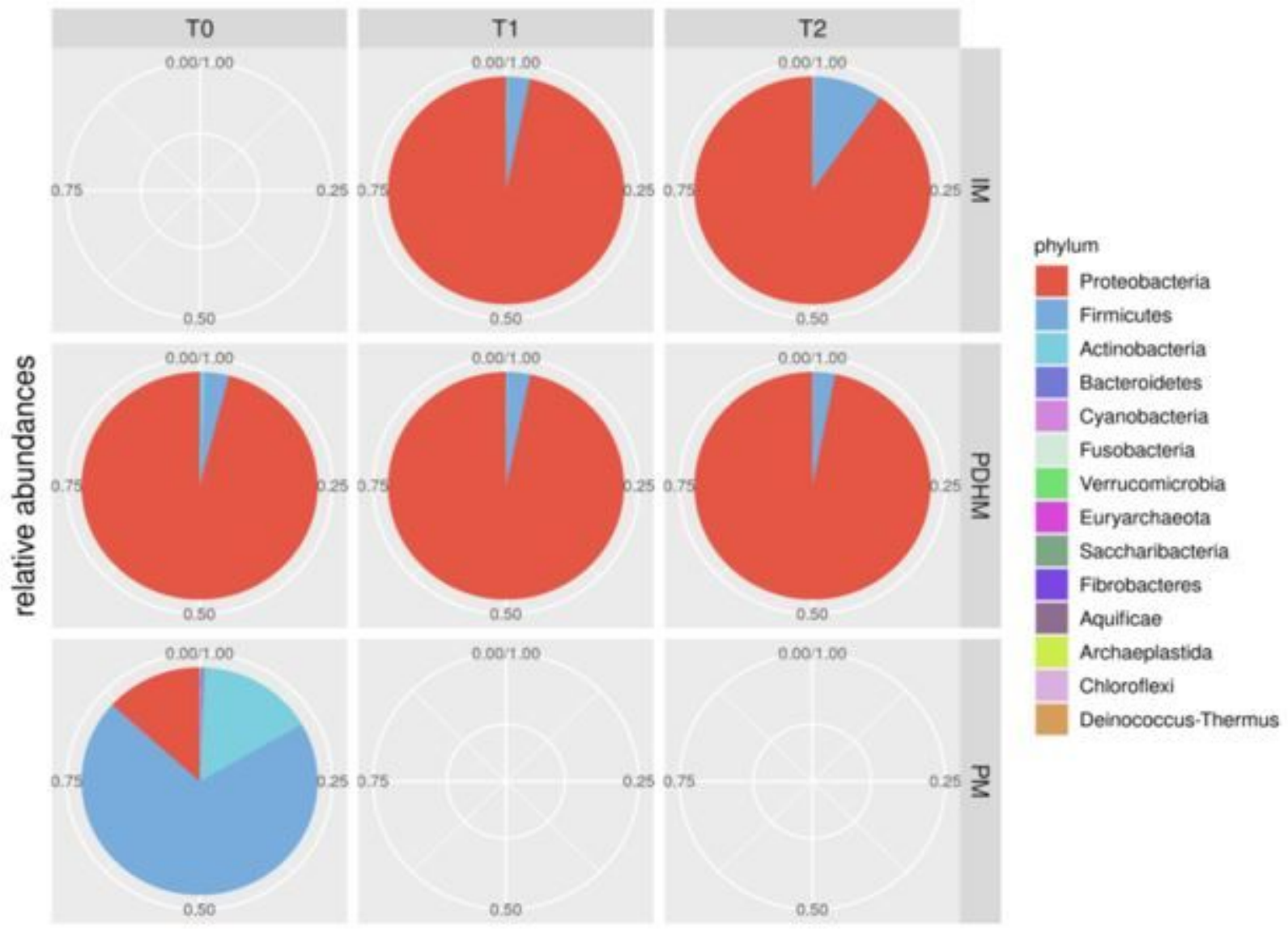

Figure 3

Pie-charts of phylum relative abundances in the PDHM, PM and IM samples. 


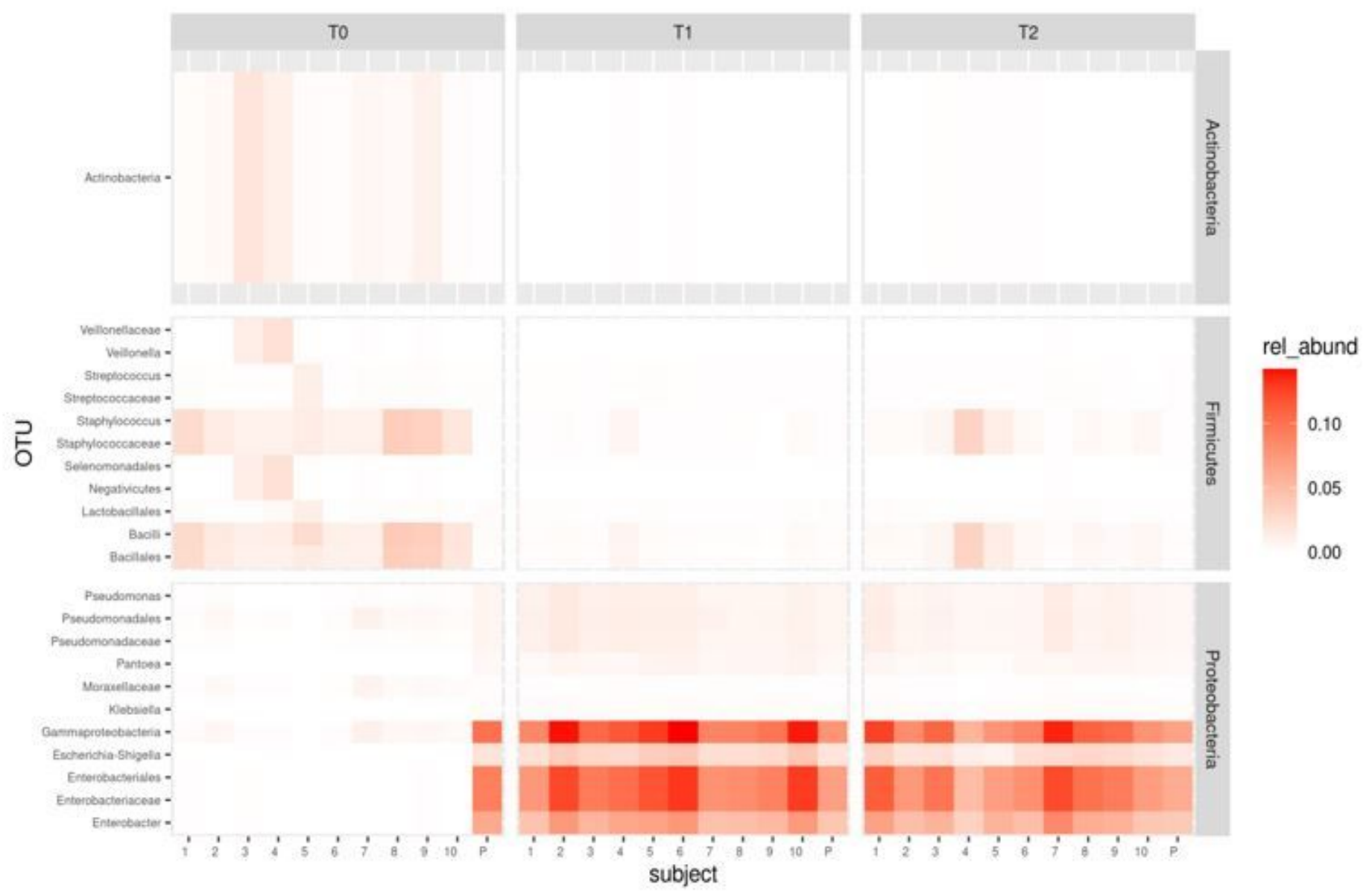

Note.

Only taxa with relative abundance $\geq 1 \%$ are shown.

$\mathrm{P}=\mathrm{PDHM}$ (Pasteurized Donor Human Milk). Numbers 1 to 10 in the figure refer to PM1 to PM10 at T0 and IM1 to IM10 at T1 and T2.

\section{Figure 4}

Heatmap of the within-phylum relative abundance of microbial taxa identified in PDHM, PM and IM samples at three time points. 

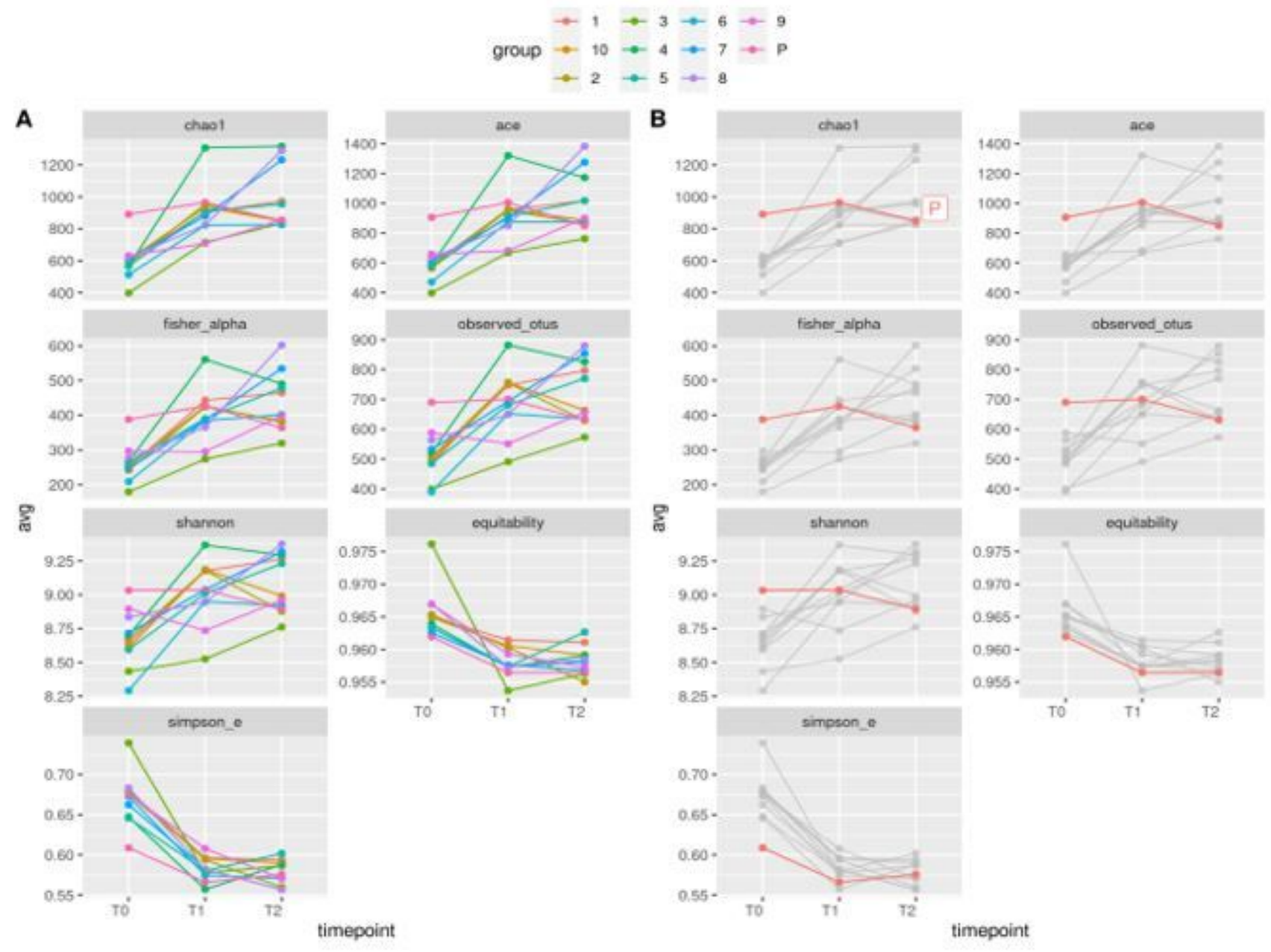

Note.

Raw values are reported in the panels A and B. Panel B shows the data obtained with the PDHM sample.

\section{Figure 5}

Alpha-diversity analyzed using different indices per time points. 
timepoint $\odot$ то $\mathbf{T}_{\mathrm{T} 1} \square \mathrm{T} 2$
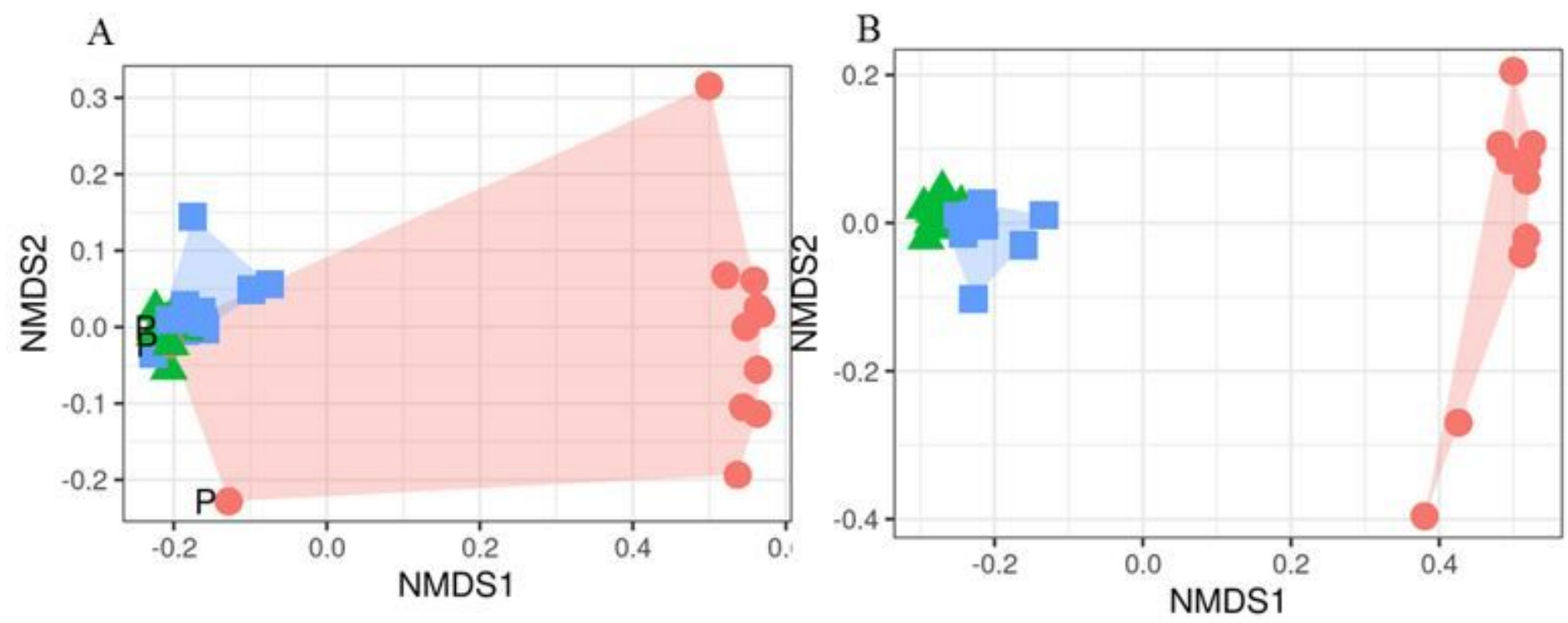

Note. P = PDHM (Pasteurized Donor Human Milk).

Samples were grouped by time point and the analysis performed with PDHM (A) or without PDHM sample (B).

\section{Figure 6}

First two dimensions from the (non-metric) multi-dimensional scaling of the Bray-Curtis dissimilarity matrix. 
A 600

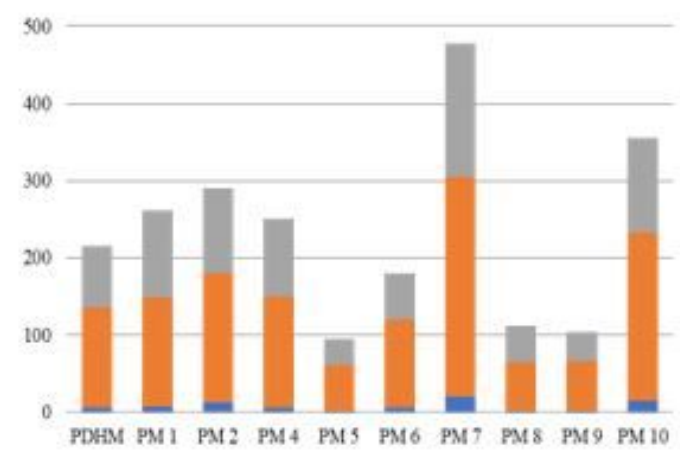

C

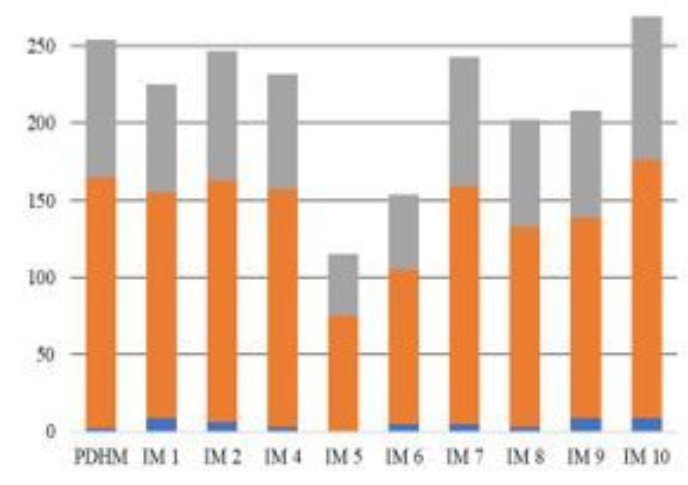

B 600
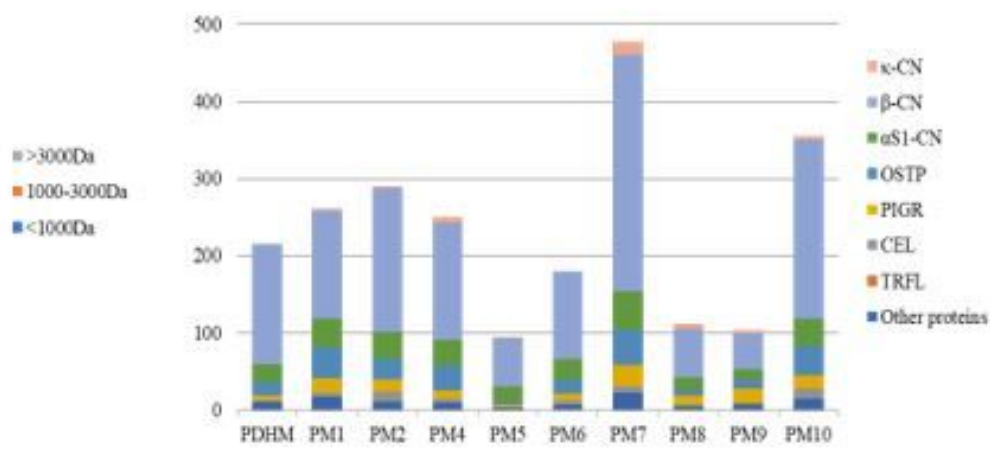

D 30

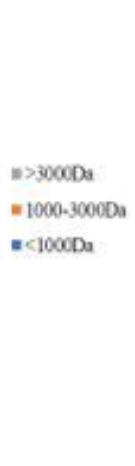

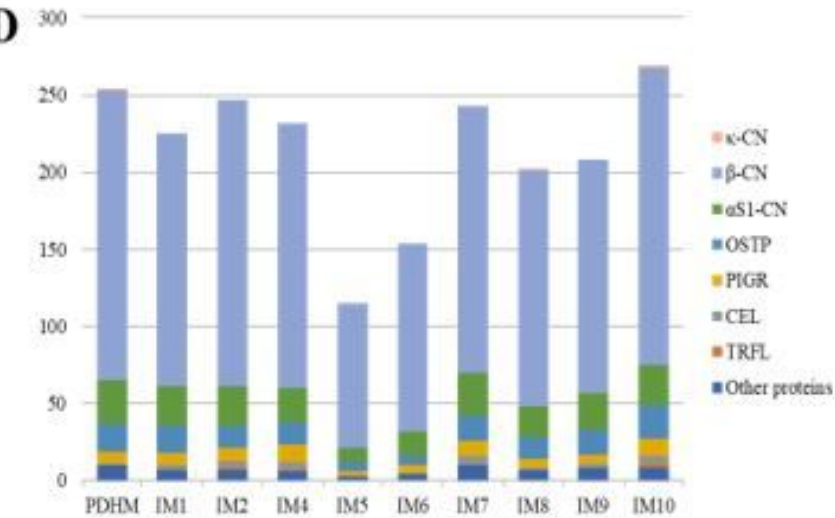

Note. Number and molecular weight distribution of the peptides identified in PDHM and PM at T0 (A) and PDHM and IM at T2 (C). Number of peptides and related precursors proteins in PDHM and PM at T0 (B) and PDHM and IM at T2 (D). ( $\kappa-C N$, $\kappa$-casein; $\beta-\mathrm{CN}, \beta$-casein; $\alpha \mathrm{S} 1-\mathrm{CN}, \alpha \mathrm{S} 1$-casein; OSTP, osteopontin; PIGR, polymeric immunoglobulin receptor; CEL, bile salt-activated lipase; TRFL, lactotransferrin).

\section{Figure 7}

Qualitative peptidomic overview of PDHM, PM and IM samples.

\section{Supplementary Files}

This is a list of supplementary files associated with this preprint. Click to download.

- AdditionalFigure1.pdf

- AdditionalTable1.pdf 